\title{
Unfolding roles and identities of professionals in construction projects: Exploring the informality of practices
}

Pernilla Gluch PhD, assistant professor

Construction Management, Chalmers University of Technology, S-412 96 Göteborg, Sweden. e-mail: pernilla.gluch@,chalmers.se

\begin{abstract}
Using a practice lens perspective, the environmental professional's role is examined in relation to social practices in construction projects. Drawing on several case studies of environmental management, the findings show that contradictory practices prevent environmental professionals from fulfilling their expected role and function. Different world-views and communication cultures as well as a perception of environmental management as bureaucratic nit-picking, create tensions between environmental work and project practice. Dealing with these tensions, environmental professionals develop alternative identities to adapt to the different situations that they find themselves in, i.e. formal roles in accordance with their job description and informal roles to suit different project practices. However, this strategy seems to result in further fragmentation between existing practices, creating barriers between professions. The study reveals four aspects that affect the professional's role: relational and positional power, professional identity, visibility, and the facilitation of meaning-making processes in the project context. The research approach taken has created an opportunity to closely follow the development of an emerging profession in construction, opening a window that allows connecting a local and situational context to a wider societal discourse of environmentalism.
\end{abstract}

Keywords: social practice, professionals, environmental management, roles, practice-based research 


\section{INTRODUCTION}

Within the construction industry, a common mode of organizing projects is by decoupling activities from the main organization and delegating responsibilities (Bresnen et al, 2004; Dubois and Gadde, 2002). Carrying out their core activities in projects has nurtured a decentralized decision-making culture, which is characterized by operational interdependence and organizational independence (Dubois and Gadde, 2002). The result is organizational divergence, which impedes communication between the main organization and the project organizations, including the flow of environmental information (Gluch and Räisänen, 2009). A challenge in project-based organizations is therefore to align permanent structures and practices of the company, such as management systems, with the temporary and operational activities performed within projects. This alignment between the temporary and the permanent can, however, be problematic; for example in the areas of knowledge management (Styhre et al., 2004), organizational change processes (Bresnen et al., 2005), management practices (Labuschagne and Brent, 2005) and adoption of innovations (Dubois and Gadde, 2002). These factors influence the interpretation of a company's long-term environmental strategies and goals, and how these are implemented in projects (Gluch, 2005). To navigate between long-term environmental strategies and the immediate concerns of operational activities on site, many companies have appointed specific persons to be carriers of environmental information between different organizational units. Currently these environmental professionals (managers and staff in environmental departments and/or in larger construction projects) select and filter the environmental information and knowledge to be transmitted within the organization (Gluch and Räisänen, 2009). Top management and project members often view them as organizational anchor persons concerning environmental issues. This involves the challenge of integrating modes of action relevant to several work practices in the organization and to individuals that might have different ways of understanding and dealing with environmental issues (Gherardi and Nicolini, 2002a).

Over the last ten years the author of this paper has been studying environmental management in construction projects and interviewed many environmental professionals. Many of the stories told during the interviews have echoed frustration at not being able to communicate environmental information to the other members of the project organization. In spite of an increased recognition of 'soft' management factors, such as environmental management, practitioners still seem to lack the necessary language to make sense of and effectively address these issues (Nicolini, 2002). As a result, the environmental professional is confronted with situations where his/her environmental values conflict with other more important imperatives, such as time and productivity, which often hinder pro-environmental behaviour (Gluch and Räisänen, 2009).

This paper builds on the work of Gehrardi and Nicolini (Gehrardi, 2009; Nicolini, 2009; Gherardi and Nicolini, 2002a \&2002b) applying a 'practice lens' perspective. This perspective regards practice as an institutionalized 'doing' which has been constructed through a social system of relations where agency is distributed between individuals and artifacts, and where practice is emergent, consisting of collective and situational actions that take place through interconnected net-works. Based on empirical observations and interviews from several case studies of environmental work in construction projects during the production phase, and assuming that roles 
are socially constructed over time, this paper examines the role and identity of environmental professionals, and discusses how these are formed, often informally, at the workplace.

First, the creation and characterization of environmental professionals in industry are described. An account of the theoretical perspective is given, showing how practices and discourses of environmentalism are constructed in organizations. Following an explanation of the research methodology, the actors' own practice-based narratives are used to show how roles and identities are shaped in construction. Finally, tensions between environmental work and project practice in relation to the role of environmental professionals are discussed.

\section{WHAT CHARACTERIZES THE ENVIRONMENTAL PROFESSIONAL?}

Although still under debate, four features are often put forward as characteristic of a profession (Mieg, 2001). First there is a common reference to a central social value that justifies the specific professional work. Second, a profession is also characterized as having a knowledge domain of professional work; a specific competence that is not shared by other professions. Third, formal training, most often a university degree, is seen as central for a profession, and fourth is the existence of professional associations.

The recent and alarming evidence of global warming and climate change has brought environmental aspects and values into focus, thereby justifying the environmental work undertaken by construction companies. The importance of these issues is now uncontested and much effort is being spent in order to diminish the environmental impact of organizations. For example, according to Gluch et al (2009), more than $70 \%$ of companies within the Swedish construction industry have an Environmental Management System (EMS). The extensive use of EMSs as a governing instrument demands extensive administration. To manage the interrelation between long-term environmental strategies and the immediate concerns of operational activities on site, many large construction companies have appointed specific persons who, often in addition to other tasks, are expected to take on the communicative role as carriers of environmental information between different organizational units in the company, such as project teams, purchasing, and sales (Gluch, 2005). In Sweden, 81\% of the companies with more than 50 employees and a main business within the construction sector have personnel working with environmental issues (Gluch et al, 2009). Most Swedish construction companies today have an environmental manager working with strategic environmental issues, and some companies also have environmental staff. Most of the environmental managers have a university degree in engineering or some other natural science discipline (SAEM, 2006).

There are various perceptions of what an environmental profession is and what environmental professionals do (Mieg, 2001). In fact the tasks that environmental professionals fulfill in their daily work have changed over the years. The work of environmental managers is often fragmented into varying tasks, and a recent questionnaire survey in Sweden (SAEM, 2006) revealed that $78 \%$ of environmental managers were also responsible for other managerial areas such as quality, risk management, and corporate social responsibility. Fragmented tasks, a specific knowledge domain and a scientifically driven work ethic make the environmental profession different to other professions within the construction industry. This means 
that the environmental professionals often seek the support from other environmental professionals outside corporate boundaries, resulting in several associations for environmental professionals, such as Environmental Careers Organization in the USA and the Swedish Association of Environmental Managers in Sweden.

What makes the environmental knowledge domain specific is the handling of highly complex and value laden environmental issues in an economically driven reality. Dobers and Wolff (1995) described the necessary capabilities of an environmental professional as: 1) needing to have an interdisciplinary knowledge base, 2) having the ability to manage organizational relations; 3 ) having the capacity to integrate and understand multiple technological processes, and 4) having the capability to create and maintain a value-based discussion within the organization. Although it is unlikely that one person would have so many capabilities, the emphasis of the organization would be on having environmental professionals who are able to read the organizational context and then adapt environmental practice and rhetoric to that context. Studies have shown that the environmental professionals' attitudes and behaviour largely influence whether the environmental work succeeds or not (Rex and Baumann, 2008). Their attitude, reflected in talk and action, determines whether the environmental professional is regarded as a nag, a trusted anchor, or an exciting inspirer (Baumann, 2000; Meima, 2002). This suggests that it is important to frame any study environmental professionals' roles and identities in stories and narratives.

\section{THE CONSTRUCT OF ORGANIZATIONAL PRACTICES AND DISCOURCES OF ENVIRONMENTALISM}

Given the focus on how environmental professionals' roles and identities are formed in construction projects, the power position of, and interaction between, actors, structures and agencies is viewed through a practice lens (Gheradi, 2009). This perspective sees practice as institutionalized way of doing something. Applying a "practice lens" in the sense of institutionalized doing, means seeing practice as emergent and collective actions of "knowing how to align humans and artifacts within a socio-technical ensemble and therefore knowing how to construct and maintain an action-net, which is interwoven and deployed so that every element has a place and a sense in the interaction' (Gherardi, 2009, p. 117). An analogous view is that environmental practices are institutions and enactments shaped by, and shaping, organizational discourses of environmentalism (Füssel, 2005; Stenberg and Räisänen 2006 ); it is a shaping process in which the environmental professional reciprocally takes part. As such, it incorporates aspects related to agency and structure in organizations (Battilana, 2006; Lindgren and Packendorf, 2007), as well as ideas on interpretation and translation proposed by discourse theory (Fairclough, 2003), sense making theory (Weick, 1995) and narrative perspectives (Czarniawska, 1997).

The practice lens perspective helps understand how interaction between actors, structures and artifacts forms institutional practices, identities and roles in a specific organizational setting (Lindgren and Packendorf, 2007; Nicolini, 2006). The implication of a practice perspective means treating environmental management as something people do and not as something it is. This means understanding how the natural environment is embedded in action, practices and structures, through a process where people are constantly involved in the act of organizing (Füssel and Georg, 2000). From the perspective of environmental professionals, this approach involves studying the role of individuals' position in the social context they are 
embedded in. It also means treating roles and identities as something that is constructed, re-constructed and maintained by daily interaction through talk and action inherently interwoven in social processes. It is in these interactions that information may be appropriated i.e. engage and become part of a person's internalized stock of knowledge, and subsequently enacted upon (Gherardi and Nicolini, 2000; Gluch and Räisänen, 2009). In this shaping process, notions of, for example, the natural environment are verbalized and translated into objects that in turn are made sense of and translated into action (Füssel, 2005; Stenberg and Räisänen, 2006). This process occurs within social systems shaped by power relations and competing discourses (Gherardi and Nicolini, 2000). Power is both restraining and enabling, meaning that power is relational and positional, which differs from the traditional view that power is a possession and a control of resources.

Gherardi and Nicolini's (2000; 2002a; 2002b) study on safety knowledge in construction shows that mastering a practice is a result of a process of active engagement in the ongoing practice of a specific community. To actively engage in and influence on-going development of project practices into a sustainable direction, environmental work and/or environmental professionals have to be visible in the organization (Gluch and Räisänen, 2009). Moreover, in this process language plays an important role in making sense of situations and contexts. Environmental practices are institutionalized through on-going organizing processes, where individuals collectively create meaning of their environmental work based on their previous understanding set in relation to their social context (Bresnen et al, 2003). For some, environmental work means safety and for others it means climate change (Stenberg, 2006). Through linguistic acts and narratives, practitioners can discover the social patterns of agency, power and practice in a specific setting: as Gehrardi and Nicolini (2002, p.216) put it "to feel the canons of the group and community by developing sensory maps". This means that practices inevitably sustain unequally empowered social positions in which discursiveness work as both the locus and object of power struggles (Nicolini, 2007). The success of practices thus rests on their compatibility with existing frames embedded in the contextual settings (Füssel and Georg, 2000).

The standpoint taken from this review is that professional roles and identities do not exist 'out-there'; they are social constructs shaped through on-going social processes of interactions between individuals, artifacts or organizations and the institutional context in which they are embedded.

\section{RESEARCH METHOD}

Following inductive research logic, this paper is based on a multiple case-study design (Yin, 2003) that clarifies how roles and identities of environmental professionals are formed in the workplace. Empirical data were collected between 1999 and 2008 from 13 different construction projects and 12 different construction companies. The projects and companies had moved beyond the piloting stage of environmental management, and had actually implemented environmental management systems and established a number of environmental routines and guidelines. This enabled the observation of the emergence of organizational and professional issues that do not show in a piloting phase (Nicolini, 2006). The projects and companies varied in size, geographical range and type. The longitudinal 
approach has facilitated, what Corbin and Strauss (2008) emphasize as important for qualitative research, an opportunity to "allow time for sensitivity to grow and for the evolution of thought to take place" (Corbin and Strauss, p. 245). Moreover, field observations, photo documentation, in-depth interviews and surveys of organizational documents enabled a triangulation process, which as multiple sources of data have strengthened reliability of the findings.

To obtain an understanding of context-specific circumstances pertaining to environmental practice, such as corporate and project-specific environmental policies, demands and management systems, several site visits were made to enable observations of situated social interaction. During these visits, data were collected by shadowing environmental professionals, which enabled the researcher to observe how they interacted with site personnel as well as permitting informal conversations with them. The site visits, which varied from one day to three weeks, were photodocumented and generated extensive field notes. Each day of the visit was ended with an unstructured interview with the environmental professional on site, which provided an opportunity for the researcher to get immediate feedback on observations and to verify interpretations. It also enabled an understanding of how beliefs, experiences, feelings and intentions are expressed in a specific setting. Furthermore organizational documents and drawings from the projects, the company intranets and management-control systems were reviewed. This methodological approach facilitated critical reflection and awareness of the interpretative activity that occurs when researchers understand the reality of what they are studying (Alvesson and Sköldberg, 2000).

In addition, in-depth interviews lasting between one to three hours with 97 construction industry actors involved in the production and dissemination of environmental information were carried out. These actors were environmental professionals at different levels of the organizations, site managers and foremen representing the contractor in construction projects, and client representatives in construction projects. The semi-structured interviews were recorded and the transcribed material was coded using procedures recommended by Strauss and Corbin (1998) and Miles and Huberman (1984). The interview excerpts were emplotted (Czarniawska, 2004) by structuring them into sentences that were intelligible and made sense for the researcher. The analysis of the interview transcripts focused on the ways in which the different actors construed their social world in their narratives. Key words, phrases and concepts were extracted, compared and contrasted, and then triangulated with the findings from similar analyses of the documents, the visual material and the field notes. Representative extracts were then selected to construct the narratives.

The approach to analyzing data took into account that narrative data are not merely a representation of events, but also represent how people make sense of their world in narrative terms and how they act in relation to their values (Czarniawska, 1997). In organization theory, works published by Czarniawska (1997, 2004), and Gabriel (2000) are widely regarded as the basis for a narrative view of organizations. The term narrative and the related terms story and storytelling compete with a number of similar terms such as talk (Boden, 1994), which underline the central importance of verbal communication in organizational activities. In the examples of narratives presented in this paper quotes are used to enable readers to interpret the material for themselves. 


\section{NARRATING THE ROLE OF ENVIRONMENTAL PROFESSIONALS IN CONSTRUCTION PROJECTS}

The focus of this paper is how roles and identities of environmental professionals are formed, often informally, in the workplace. The standpoint is that these roles and identities do not exist 'out there', they are social constructs shaped through on-going processes of interactions between individuals or organizations and the institutional context in which they are embedded.

\section{Relational and positional power}

Being decoupled from where the production takes place made the environmental professionals feel torn by a situation where, due to limited time-resources, they were dependent upon two communities with different world views: the environmental staff and the project organizations. As illustrated by the following stories, the organizational distance between the environmental professional and the project organization made the environmental organization impersonal, which hindered a smooth relationship between the parties.

Sure, I can call some environmental dude in my division, I don't recall his name, but there are many who call him and he does not have time to help us. (Site managerl)

It has been the intension that Ola shall be more involved in the projects, but he isn't, why I don't know. I guess he has a lot of other tasks to deal with... Top management says it is important but they do not invest enough resources to make it happen for him or for anyone else either. ...But Ola is interested and I know he wants to be on the site. He usually visits once or twice per project, but then people instead become irritated. It's not him, it is his role as a 'paper tiger' that irritates them. (Site manager2)

For instance when they do an environmental impact assessment during the planning phase, and then it is launched in 'reality'. What happens? Nothing, they just eat this shit. And there we have a poor environmental dude in the middle of this, that has never faced our reality and he gets crushed and what does he get from this. He only gets crap. (Site manager3)

The second and third narrative point to a lack of relational and positional power in construction projects. The environmental professional is expected to act as support and filter of environmental knowledge to and from the project. What complicates this role is the inability to enforce actions in the project. Although some are positioned at an operational level, their tasks are not operative in relation to the production, with the consequence that although they may be entitled 'managers' they wield no power in the project. The 'paper tiger' metaphor in the second narrative is used in the sense of someone who is seemingly powerful but who in reality lacks real influence.

Since environmental professionals are neither empowered nor have an influential authoritative position, their role and their possibility to take action are undermined, which the following narratives show.

The thing is that I was almost burnt out. It became too much, I did not get 
any response on the issues I worked with. I left for a month because I felt that it didn't matter if I was there or not, they didn't listen to me anyway. It was very stressful working with these issues that nobody seemed to care about. Because I have no self-interest doing this job, it's not like I am extremely interested in chemicals and stuff. (Environmental coordinator1)

Through their role as specialists, environmental professionals have a knowledge advantage within a field often emphasized as strategically important for a company. However, instead of being empowered by this knowledge advantage, the findings suggest that it creates tension by challenging the site manager's traditional role as omniscient on site. As a result, which the next narrative illustrates, the project practitioners reacted negatively to the work done by the environmental professional.

Honestly, I think they [environmental professionals] are perceived as rather annoying because they have questions that you cannot respond to because you do not have enough knowledge. Usually you as site manager always have answers and in this case you don't, which is stressful. (Site manager 4)

\section{The importance of being visible}

Since environmental professionals often possess little or no power, they are unable to influence managers or workers on site. To handle this situation, many resort to persistent nagging as part of a wearing-down strategy.

She came running and after persistent nagging, she eventually got some papers from us. If nobody runs around and nags they would not get any documents. It's as simple as that. (Site manger5)

'A hydraulic wire broke, did you use spillage utilities?' 'Yes'. So where is the waste?' 'I put it in the environmental container.' 'Ok, did you fill it up again?'... Sometimes it's like a childcare centre (laugh), you can say one thing and the next second it is forgotten. To make them (the craftsmen) listen you have to nag and repeat and sometimes also show that you are angry and annoyed. (Environmental coordinator2)

You have to show on site, you have to be active and show that you exist; you can't sit in your office waiting for them to call, it is very important to be active and visible in the organization. (Environmental managerl)

The importance of visibility is emphasized by these narratives. By running around and nagging, the environmental professionals gain visibility in the organization with the result that environmental concerns also becomes visible. However, it also shows that due to different organizational structures and social processes of the involved parties, grounded on different ontologies and work-views, there is a lack of coherence concerning the status, definition and importance of environmental conduct. Rather than being anchors, the environmental professionals often perceive themselves, and were indeed perceived by project members, as a nag or a pain.

To make it work I try to help rather than barge in. But some perceive me as a pain in the ass because I demand things. 'But this is how we always have done it, why do we have to change'. That's what I have to deal with. They are starting to grasp it now after four years, to understand more, 
but still the environmental routines is not in place, which is a challenge. (Environmental manager2)

One disadvantage with this job is that you sometimes are regarded as a nag and as difficult because you make demands. You say: 'You cannot use this product.' 'Yes I know but only for this time, we are in a hurry, we have a deadline to meet' and, well, sometimes you have to turn a blind eye to it, but at least you try to make them think ahead. (Environmental coordinator 3)

As indicated by the narratives, environmental professionals have to deal with situations in which their personal beliefs and ideology conflict with the productionfocused and time-pressed agenda of construction project practice. Handling this balancing act between personal and professional convictions and existing and institutionalized frames of project practice could put undue pressure on these officials.

\section{Finding a professional identity and belonging}

Environmental professionals are often sorted under a middle manager, which does not only decouple them from the project organization but also decouples them from each other. This does not nurture networking or the creation of a fruitful experiencesharing community within the organization. The environmental professionals perceived themselves as rather isolated in their organizations. However, in their role as specialists, they have to be keen and open to societal changes as well as to organizational needs. To handle this situation there seemed to be a tendency for them to actively search for networks and professional communities outside their organizational boundaries. Within these communities they found support on how to deal with their role, which seemed difficult to find within their own organization.

About her contact with environmental professionals at other organizations: I call Sara and terrorize her with questions; we also try to meet once a month and share ideas. And I have Karin and we try to cooperate, I check with her a few times a year about her work, if there is something new. (Environmental manager 2)

I get information from my external environmental network. That is the main reason why I have joined the network, not so much for their sake but for my own sake [laugh]. (Environmental manager3)

Sometimes being the only one appointed with specific environmental work in an organization puts environmental professionals in the somewhat ambiguous position of being both generalist and specialist. Many of the interviewees perceived this dual identity as difficult. On one hand they had to manage the difficulty of combining a strategic, policy-based, all-embracing and long-term perspective relevant for their company's whole business and on the other hand they had to gain profound expertise within a targeted field of knowledge. They needed to be persistent in their role, which unfortunately was not always easy since the profession lacks a clear career path. For this reason, many move on to different jobs before they have had time to take on a particular organizational identity.

The career opportunities are limited. There are few ways to advance in this large company. We have one head environmental manager. One way 
is to specialize, do research, but there are not that many opportunities there either. The average time in my position in this company is, I think, one and a half years. (Environmental coordinator 4)

Having an overview is of course good, coordinating and so on.... But it also has to, as I like to express it, be someone that is used to have some dirt under the nails. (Site manager1)

The environmental professional is often someone with a university degree, younger than the average person in the company, often rather newly employed, sometimes also with a non-engineering background and not seldom a women. All these factors seem to contradict the traditional norms of construction project members, as 'someone with dirt under their nails', which complicate their professional identity. Being regarded as the secretary, as in the second narrative below, does nothing to strengthen their professional status or identity within the organization.

It is difficult being a young woman and coming to the sites. You get stepped on and you walk on some mines before you learn how to deal with certain people. (Environmental coordinator5)

Some see me as a secretary that arranges the paper work for them, and that's it. (Environmental manager 4)

Using standardized EMS bureaucratizes environmental work to the extent that it is often perceived as administrative routines, maintaining a level considered as hygienic, and efforts other than the minimum considered as burdensome. For the environmental professional this often results in them being characterized as paper chasing bureaucrats. However, the continuous improvement idea of EMS requires a certain degree of control of practice and processes through continuous assessments by the environmental professional. This sets them in a controlling position which is perceived as negative by practitioners and is why many environmental professionals seek ways to tone down their role as controllers. Accordingly, they use words, such as coach and collaboration to describe their role, which has a more positive ring to it.

Traditionally it is a control function but I try to make it less controlling. I like to see it as a collaboration between parties so we don't get the 'oh here's the environmental lady again, and she is going to control our paperwork'. It is better if we find an atmosphere where we try to make it a positive thing to do. It is not easy... However I have to make them understand that controlling their work is my job, that's what I'm hired to do, they can complain and say I'm a pain in the neck, but it's only my job. (Environmental coordinator 6)

I'm a coach and as a coach I can point out to them: 'watch out, there are better alternatives'. But I can never stop operations, and I can never act as an 'environmental police officer'. (Environmental manager5)

The previous and the following narratives indicate that environmental professionals are aware of their perceived awkward role as paper tigers and environmental police officers and therefore actively reconcile their role with the practice of construction projects. 


\section{Searching for a language to create meaning}

Even though environmental impacts caused by the construction process may extend beyond the project closure, the environmental boundaries are often mentally restricted to the time span of the project. This means that the environmental problems in a project are regarded as 'momentary' in that they occur during the project's life span and when the project is finished so too are the problems. Consequently, project members' commitment to environmental issues is constrained by the project's time and space boundaries. Environmental concerns are often subject to tensions between the long-term strategies and norms of management and the short-term, time-pressed reality of projects. The following narrative illustrates the complexity environmental professionals have to deal with: they must show enthusiasm, they must inspire, they must understand the construction process as well as its complexity, and they must be careful not to be seen as fanatic.

To manage your situation you have to find this issue [environmental] fun and interesting. Be enthusiastic and feel for it. But also you need to understand the context; preconditions, plans of actions, budget, relationships, laws and all. You need to understand the construction process. It's a great advantage if you understand the construction process; an environmental fanatic may stray from the point with environmental stuff without any grounding in the production. It is important to be on site and see how it works, see, discuss and understand solutions. See and squeeze material tubes, discuss with the client, ask yourself 'where does the gravel come from?' (Environmental manager 6)

The narrative emphasizes the importance of sharing a language so that environmental issues can be understood in a specific situation and context. When communicating environmental information, the environmental professional therefore has to deal with both the project-defined perspective of project success and the long-term perspective of environmental responsibility. In the following narrative the interviewee describes how he continuously tries to find a level that matches project practices, a process he refers to a "somersault".

In my role it is important to find an entrance to the projects, an entrance that neither shoot above the target nor under, is simply right on target. The challenge is to make sure that our personnel and our competence level matches our goals and that our administrative routines are practical and useful so they do not 'gather dust on the bookshelves'. My role is to choose the correct spices in this soup and not make it too watery. We need to simplify, decrease the burden for our site personnel and at the same time improve our environmental work. That is the somersault I try to do. (Environmental manager 6)

We need to discuss these issues on site; it's not enough with written reports and other paper producing routines. (Site manager 7)

I mean, the environmental coordinator, he collects statistics on machinery that are to be sent to the client every month, and the questions is; what are they good for? I have never been informed why, I have no clue, and it doesn't feel meaningful. The poor coordinator, all the work he has to put into it and for... nothing, as I see it. I can't see that we improve the environment by sending in these statistics. I don't know, pure 
bureaucracy, that's my interpretation of it... (Site manager 6)

The extensive use of EMS as a governing instrument demands extensive written reporting, which requires a text-based communication culture. The second and third narrative above indicates that the communication culture as set by EMS and other reporting routines conflicts with the oral face-to-face communication that is the most common and preferred mode of interaction in construction project practice. The third quote also shows how the role of an environmental professional may be formed through the practices of excessive control and detailed reporting routines for 'the poor someone dealing with the nothing'.

\section{DISCUSSION}

Applying a practice lens perspective, this paper has explored how environmental professionals frame and form their role and identities in relation to project practice. It has revealed four aspects affecting the environmental professional's role: relational and positional power, professional identity, visibility and the facilitation by project members of processes to create meaning of environmental issues in the project context. Findings show that to deal with tensions between environmental work and project practice, environmental professionals develop alternative roles in order to adapt to the different situations that they find themselves in. In other words, they create formal roles in accordance with their job description and informal roles to suit different project practices. As such, project practices frame as well as constrain the role of environmental professionals and how, or if, they are empowered within their organization. Although the environmental professional could potentially wield power through a knowledge advantage, this is perceived by the practitioners as a possible threat towards the site manager's traditional role as site leader and as a disruption of institutionalized order within project practice. The stories also revealed that environmental issues risked being negotiable or even being ignored due to the inequality between those actors with environmental knowledge and those with decision-making power for the outcome of the construction project. This indicates that environmental practices are not yet a part of project culture and practice and that environmental professionals still search for ways to deal with project practices without jeopardizing their environmental mission.

The findings point to the importance of environmental professionals' having a clear identity within the project setting. Today, the opposite rather applies since the qualifications, education, work tasks and organizational position of the role remain ill defined and informal. It was observed that instead of being seen as important actors for organizational and collective learning, environmental professionals were regarded as 'nitpicking nags'. To be heard in the project organization, the environmental professional has to be familiar with and adapt to the 'rules of the game' as well as the 'language games'. Thus, they have to adapt to the social patterns that guide agency, power and practice in a specific setting (Gherardi and Nicolini, 2002a). Bresnen et al (2003) similarly found that the success of new management functions depends on interpersonal and cultural aspects more than on technological and procedural mechanisms. At present it appears that environmental discourse and project practice discourse do not tune into a shared language and direction, and environmental professionals need to have a strong sense of integrity that can give them the strength to counteract project practices that may prevent them from fulfilling their environmental responsibilities. 
In line with Gherardi and Nicolini's (2000) studies on safety in construction, the findings also showed how visibility facilitates active engagement in the on-going project practice by providing an opportunity to master that practice. A clearly visible position of the environmental professional would help strengthen the environmental mindset and discourse in the organization. This means being an active, legitimate member of the project organization and laying the groundwork for a shared understanding of what green building is and why it is considered necessary to build green. Nevertheless, as their role has been framed, the opportunity for environmental professionals as well as environmental concerns to be visible in the project organization was found to be constrained by the isolation of the project organization from the permanent environmental organization and vice versa.

More, the findings emphasize the importance of environmental practices for creating meaning for project members in their everyday work. The reliance on a top-down standardized EMS as guidance for project members to act pro-environmentally not only contradicted the pro-experience and trouble-shooting culture of construction (Knauseder, 2007), but also restricted the environmental professionals' as well as the project practitioners' opportunities to be innovative and creative in their roles. The consequence is that environmental professionals are often forced into situations where they have to juggle between weak environmental practices and dominant institutionalized project practice.

\section{CONCLUSIONS}

The paper has argued that due to different organizational aspects and oftentimes contradictory practices, the role and identity of environmental professionals as environmental agents are thwarted. Different time-perspectives and communication cultures, where environmental communication is often perceived as bureaucratic nitpicking, hinder the meaning-making process of why environmental work is important. The unequal relationship between organizing the project and organizing environmental concerns gives rise to a mismatch between practices and between professions; a strong and rather institutionalized construction project management profession and a weak and still emergent environmental management profession. The result is an unequal power struggle, where the way that environmental work is organized creates further fragmentation (or diversification) between existing practices rather than aligning them, putting up barriers between professionals in the built environment.

This paper should be seen as a contribution within an emergent field of research that focuses on social practice and the role of environmental professionals in construction. Due to an increased societal emphasis on environmental sustainability, this role has meaning but has yet to develop a professional identity, visibility and an authoritative position in project-based organizations. The paper also emphasizes a need for further research that studies the emergence of new professional roles in construction and how these challenge old power bases and professional expertise. The research approach, where in-depth interviews have been combined with field studies and shadowing of environmental professionals has enabled an opportunity to examine the informality of the role of environmental professionals. In addition, the time-span of the study has created an opportunity to closely follow the development of an emerging profession in construction, opening a window that allows connecting a local and situational context to a wider societal discourse on environmentalism. 


\section{Acknowledgements}

I would like to thank all the environmental professionals and others that generously shared their stories with me. I would also like to thank four anonymous reviewers and the guest editors for their constructive critique on draft versions of this paper.

\section{REFERENCES}

Alvesson, M and Sköldberg, K (2000) Reflexive Methodology - New vistas for qualitative research, Sage, London.

Battilana, J (2006) Agency and Institutions: The enabling of individuals' social position. Organization, 13, 653-676.

Baumann, H (2000) Introduction and organisations of LCA activities in industry: descriptions and analysis of two LCA project in Swedish companies. International Journal of Life Cycle Assessment, 5(6), 363-368.

Boden, D (1994) The business of talk: Organizations in action, Cambridge, Polity Press.

Bresnen, M, Edelman, L, Newell, S, Scarbrough, H, Swan J. (2003) Social practices and the management of knowledge in project environments. International Journal of Project Management, 21, 157-166.

Bresnen, M, Goussevskaia, A, Swan, J (2004) Embedding new management knowledge in project-based organisations. Organisation Studies, 25(9), 1535-1555.

Bresnen M, Goussevskaia, A, Swan, J. (2005) Implementing change in construction project organizations: exploring the interplay between structure and agency. Building Research and Information, 33(6), 547-560.

Corbin, J and Strauss, A (2008) Basics of Qualitative Research, 3rd ed., Sage, Thousand Oaks, CA.

Czarniawska, B (1997) Narrating the Organization, The University of Chigaco Press, Chicago.

Czarniawska, B (2004) Narratives in social science research, Sage, London.

Dobers, P and Wolff, R (1995) Managing ecological competence: Empirical evidence and theoretical challenges. Greener Management International, 11, 32-48.

Dubois, A and Gadde LE (2002) The construction industry as a loosely coupled system: implications for productivity and innovation. Construction Management and Economics, 20, 621-631.

Füssel, L (2005) Introduction, in Füssel, L. (ed), Corporate environmental governance - perspectives on organising and communication, Studentlitteratur, Lund, Sweden. 
Füssel, L and Georg, S (2000) The institutionalization of environmental concerns. International Studies of Management and Organization, 30(3), 41-58.

Gabriel, Y (2000) Storytelling in organizations: facts, fictions, and fantasies, Oxford University Press, Oxford.

Gherardi, S (2009) Introduction: The critical power of the 'practice lens'. Management Learning, 50, 115-128.

Gherardi, S and Nicolini, D (2002a) Learning the trade: A culture of safety in practice. Organization, 9, 191-223.

Gherardi, S and Nicolini, D (2002b) Learning in constellation of interconnected practices: Canon or dissonance. Journal of Management Studies, 39(4), 419-436.

Gherardi, S and Nicolini, D (2000) To transfer is to transform: The circulation of safety knowledge. Organization, 7, 329-348.

Gluch, P (2005) Building Green: Perspectives on Environmental Management in Construction, Dissertation thesis, Chalmers University of Technology.

Gluch, P, Brunklaus, B, Johansson, K, Lundberg, Ö, Stenberg, A-C, Thuvander, L (2009) Environmental attitudes, management and performance. In Performance Improvement in Construction Management (Eds. Atkin B. and Borgbrant J.), Taylor and Francis, London.

Gluch, P and Räisänen, C (2009) An interactional perspective on environmental communication in construction projects. Building Research and Information, 37(2), 164-175.

Knauseder, I (2007) Organizational learning Capabilities in Swedish Construction Projects. Dissertation thesis, Chalmers University of Technology.

Labuschagne, C and Brent, AC (2005) Sustainable project life cycle management: the need to integrate life cycles in the manufacturing sector. International Journal of Project Management, 23, 159-168.

Lindgren, M and Packendorff, J (2007) Performing arts and the art of performing on co-construction of project work and professional identities in theaters. International Journal of Project Management, 25, 354-365.

Meima, R (2002) Corporate Environmental Management - Managing (in) a new practice area. Dissertation thesis, Lund University.

Mieg, HA (2001) Professionalization and professional activities in the Swiss market for environmental services. In W. Leal Filho (ed.) Envionmental Careers, Environmental Employment and Environmental Training, Peter Lang, Frankfurt-amMain, Germany.

Miles, MB and Huberman, AM (1984) Qualitative Data Analysis: A Sourcebook of New Methods, Sage, London. 
Nicolini, D (2002) In search for 'project chemistry'. Construction Management and Economics, 20, 167-177.

Nicolini, D (2006) The work to make telemedicine work: A social and articulate view. Social Science and Medicine, 62, 2754-2767.

Nicolini, D (2007) Stretching out and expanding work practices in time and space: The case of telemedicine. Human Relations, 60, 889-920.

Nicolini, D (2009) Articulating practice through the interview to the double. Management Learning, 40, 195-212.

Rex, E and Baumann, H (2008) Implications of an interpretive understanding of LCA practice. Business Strategy and the Environment, 17(7), 420-443.

SAEM (2006) Miljöchefen: NMC-enkäten 2006 (trans. The Environmental Manager: SAEM questionnaire 2006), Swedish Association of Environmental Managers.

Stenberg, A-C (2006) The Social Construction of Green Building: Diachronic and Synchronic Perspectives. Dissertation thesis, Chalmers University of Technology.

Stenberg, A-C and Räisänen, C (2006) The interpretative flexibility of "green' in the building sector: Diachronic and synchronic perspectives. International Studies of Management \& Organization, 36(2), 32-54.

Strauss, AL and Corbin, J (1998) Basics of Qualitative Research, $2^{\text {nd }}$ ed., Sage, Thousand Oaks, CA.

Styhre, A, Josephson, P-E, Knauseder, I (2004) Learning capabilities in organizational networks: case studies of six construction projects. Construction Management and Economics, 22, 957-966.

Weick, KE (1995) Sensemaking in organizations, Sage, Thousands Oak, CA.

Yin, R (2003) Case study research: design and methods, Sage Publ., London. 